\title{
FRONTERAS, LIBERALISMO E INMIGRACIÓN ${ }^{1}$
}

\author{
DANIEL LOEWE \\ Universidad Adolfo Ibáñez \\ (Santiago de Chile)
}

\begin{abstract}
RESUMEN: el artículo sostiene que la teoría liberal está tensionada por una pretensión de universalidad normativa y su implementación institucional en el contexto de los Estados nacionales. Esta tensión se expresa claramente en el caso de la inmigración con la demanda estatal de control discrecional de las fronteras. El artículo desarrolla cuatro argumentos a favor de la relevancia normativa de las fronteras (espacios de seguridad; bienes públicos y fair play; justicia distributiva; y autonomía personal), y sostiene que no son conclusivos. Correspondientemente, desde una perspectiva liberal se dispondría de menos argumentos para justificar el cierre discrecional de las fronteras.
\end{abstract}

PALABRAS CLAVE: inmigración, liberalismo, Estado nacional, seguridad, bienes públicos, justicia distributiva.

\section{Borders, liberalism and immigration}

ABSTRACT: According to the paper, the liberal traditions are stressed by a theoretical claim of normative universality and the restriction of this claim to the context of national states. This tension is clearly expressed in the case of immigration by the state's claim for discretionary control borders. The article develops four arguments for the normative significance of borders (spaces of security; public goods and fair play; distributive justice; and personal autonomy) and contends that they are inconclusive. Correspondingly, a liberal perspective would provide fewer arguments to justify the discretionary closure of borders.

KEY WORDS: immigration, liberalism, nation State, spaces of security, public goods, distributive justice.

Vivimos en un mundo de Estados nacionales que reclaman discrecionalidad absoluta en el control de sus fronteras. Cuando renuncian al control, lo hacen en razón de tratados bi- o supranacionales que ellos mismos, en contextos de mayor o menor presión, suscriben (como en el caso de la OMC). El caso ejemplar en que se reconoce obligaciones morales que debilitan esta discrecionalidad absoluta es el de los refugiados, que se guía por la Convención de Refugiados de Ginebra, pero cuyo espíritu y también letra los Estados en su práctica actual rara vez cumplen ${ }^{2}$. Cuando se trata de inmigración (no de refugiados), los Estados se restringen a reconocer un derecho humano a emigrar que, en ausencia de un derecho a inmigrar, tiene un valor muy restringido (art. 13.2 de la Declaración Universal de Derechos Humanos). Así, retienen la potestad para decidir discrecionalmente quién puede cruzar sus fronteras para radicarse, o incluso visitarlos.

\footnotetext{
1 Este trabajo se inscribe en el Núcleo Modelos de Crisis (NS130017).

2 La interpretación corriente de este derecho es extremadamente restrictiva, aunque hay buenas razones para entenderlo de un modo considerablemente más amplio (compare Loewe 2010a).
} 
Si hay Estados —en plural-, hay fronteras entre ellos. Los liberales corrientemente hacen suya la estructuración mundial en Estados nacionales, considerándolos en ocasiones incluso como los sitios en que se articulan las demandas de justicia. Este es el caso de la teoría de justicia de Rawls (1971, 1993). Esto es desconcertante. En su fundamentación normativa las diferentes versiones del liberalismo recurren al individualismo normativo (los individuos son la última fuente de valor moral o, en otra versión, los individuos son las entidades con valor moral), al igualitarismo (en algún nivel fundamental los individuos y sus intereses valen lo mismo) y al universalismo (todos los individuos cuentan). Pero las fronteras ponen en cuestión el individualismo, al subordinar el valor de los individuos al valor de la autonomía colectiva de los Estados nacionales; ponen en cuestión la igualdad, al no otorgar el mismo valor a los intereses de miembros y no miembros; y ponen en cuestión el universalismo, al sostener que los principios liberales encuentran su implementación primaria dentro de los Estados nacionales. Pero el liberalismo no dispone de ninguna teoría sobre la legitimidad normativa de las fronteras (O`Neill, 2000: cap. 9).

En este artículo analizo cuatro argumentos - ciertamente, no se trata de una lista exhaustiva - articulados en un contexto liberal a favor de las fronteras y su control discrecional por parte de los Estados en el caso de los inmigrantes. (1) Primero me refiero a la tensión entre la doctrina liberal y la demanda de los Estados nacionales de control discrecional de sus fronteras. (2) Luego examino cuatro argumentos para dar cuenta del valor moral de las fronteras: (i) las fronteras como necesarias para generar y delimitar contextos de seguridad, (ii) en los cuales se generan bienes públicos y se puede implementar un principio de fair play; (iii) como necesarias para generar y mantener los recursos motivacionales requeridos por la justicia social; (iv) y como necesarias para posibilitar la autonomía personal. (3) En tercer lugar examino estos argumentos y sostengo que su extensión normativa es reducida y que, por tanto, no pueden justificar la discrecionalidad estatal absoluta en el caso de la inmigración. (4) Finalmente, obtengo algunas conclusiones.

\section{LIBERALISMO Y FRONTERAS}

Las teorías suelen funcionar razonablemente bien en espacios acotados, más allá de los cuales surgen dificultades. Esto vale en el caso de la filosofía moral y política, y en este contexto, también en el caso de la teoría liberal. El espacio teórico de comodidad normativa liberal se expresa en el lenguaje de las obligaciones o derechos universales, y de las obligaciones o derechos especiales consensuales (Lomasky, 2001; Sandel, 2010; Loewe 2010c).

Por una parte, teorías liberales del más variado tipo reconocen la existencia de algún paquete de obligaciones universales hacia todos aquellos a quienes se considera sujetos morales. Inversamente, estas obligaciones universales se 
expresan como derechos subjetivos, es decir, derechos de los miembros de una cierta clase de individuos. Por cierto, la composición de la clase de los sujetos morales es objeto de controversia ${ }^{3}$. Pero de un modo general los liberales hacen suyas las intuiciones humanistas universalistas y extienden estas obligaciones al menos a todos los seres humanos. En este sentido, suelen ser teorías antropocéntricas universales. Así, la semántica de los derechos humanos se integra sin dificultades al contexto argumentativo liberal. Por otra parte, las teorías liberales dan cuenta de aquellas obligaciones especiales (obligaciones que debemos a algunos agentes, pero no a otros) cuya fuerza vinculante se retrotrae a la voluntariedad, ya sea expresa o tácita: es la voluntad del sujeto la que funda la obligación y por tanto el derecho correspondiente. Se trataría, por tanto, de obligaciones consensuales. Las promesas, y por extensión los contratos, son claros ejemplos de este tipo de vínculo normativo ${ }^{4}$. Mediante promesas o contratos me impongo una obligación hacia el receptor de la promesa o la parte contratante, que a su vez adquiere un derecho al cumplimiento de mi obligación. Otros sujetos pueden beneficiarse del cumplimiento de la obligación, pero no pueden ser receptores de la obligación [en términos kantianos, es la distinción entre «obligaciones hacia» (gegenüber) y «obligaciones en vista a» (in Ansehung von)].

Evidentemente, los liberales reconocen que los individuos no son átomos aislados. El individualismo liberal es normativo, no sociológico ${ }^{5}$. Los individuos viven en familias - con diferentes estructuras-, tienen múltiples grupos de adscripción, amigos e identidades colectivas, etc. Y en estos contextos

3 Las preguntas relativas a los márgenes de esta clase son difíciles. Están los márgenes sincrónicos. Como es conocido aquí se encuentran humanos que no son —-todavía, o no serán nunca- personas (fetos; deficientes mentales severos, etc.), y personas que no son humanos (ejemplarmente, el caso de los animales no humanos). Además, están los márgenes diacrónicos, que refieren a personas que aún no existen e incluso quizás que no llegarán a existir, y quizás a aquellas que ya no existen. Aquí surgen los temas de la justicia intergeneracional y anamnética. Si bien he tratado estos temas (LoEwe, 2010b, 2011, 2014, 2015a, 2016a), los argumentos de este texto no suponen ni prejuzgan ninguna respuesta a esas preguntas.

4 Hay múltiples debates acerca de la relación entre la promesa y la obligación. Para Joseph Raz se trata de una relación inmediata: al prometer (prometo X) comunico la intención de cumplir una obligación de realizar cierta acción $(1972,1988)$. Habría un principio moral válido de acuerdo al cual obligaciones pueden ser generadas del modo expuesto. De acuerdo a otros autores, la relación estaría mediada por principios morales de más amplia aplicación (АтіуAн 1981; MACCoRmick 1972). Desde esta perspectiva, cada vez que se realizan determinadas acciones se incurre en cierto tipo de obligaciones con independencia de si se pretendía incurrir en ellas. Así, promesas generan obligaciones porque inducen a confiar (reliance theory). En este tipo de teorías una discusión usual refiere a si lo que debiese contar como el vínculo generador de la obligación es la intención de inducir confianza o la generación de la confianza.

5 Es por eso que las críticas comunitarias al liberalismo a menudo equivocan su objeto. Sostener que el individualismo normativo se encuentra a la base del liberalismo es algo diferente al objeto de las críticas comunitarias. No se trata ni de un individuo atomizado (TAYLOR, 1985), ni el sí-mismo desconectado (SANDEL, 1982). El liberalismo puede afirmar el carácter social de los seres humanos. 
se suele reconocer obligaciones y derechos especiales que, en muchos casos, no parecen ser consensuales. Entre otros, este es el caso de las obligaciones entre familiares, amigos, miembros de grupos culturales y, en ciertas interpretaciones, miembros de naciones (compárese Tamir, 1993; Kymlicka, 1989, 1995; Miller, 1995, 2007; MacCormick, 1999; Casamiglia, 2000). Es aquí, entre el universalismo de las obligaciones o de los derechos y el individualismo de las obligaciones especiales consensuales, donde se comienza a abandonar el espacio de comodidad de la teoría liberal. La pregunta incomoda es: ¿cómo dar cuenta dentro de este espacio conceptual de aquellas obligaciones especiales no consensuales?

Por cierto, hay estrategias para dar cuenta de estas obligaciones en tanto obligaciones consensuales o en tanto obligaciones universales especificadas. Un ejemplo de la primera dirección argumentativa es sostener que los derechos particulares de los hijos hacia sus padres o las obligaciones de éstos hacia los primeros se retrotraen a un tipo de consenso: aunque los padres no escogen el hijo particular que tienen, y en muchos casos ni siquiera escogen llegar a serlo, al incurrir en prácticas sexuales que pueden resultar en el engendramiento, se imponen obligaciones hacia sus hijos que son diferentes y más exigentes que aquellas que tienen hacia los hijos de los otros (Höffe, 1995: 182). Un ejemplo de la segunda dirección argumentativa es que los derechos particulares de los hijos hacia sus padres o las obligaciones de éstos hacia los primeros se retrotraen a una convención útil: cada cual se debe preocupar prioritariamente por el bienestar de sus hijos antes de preocuparse por el bienestar de extraños. Siguiendo a Nussbaum, si bien no pensamos que nuestros niños son moralmente más importantes que los niños de los otros, aceptamos que cada cual privilegie a los suyos, porque su cuidado «se llevaría a cabo de modo miserable si uno piensa que es igualmente responsable de todos» (1996: 13). La convención es útil porque es eficiente. Por una parte, se relaciona con la distribución del conocimiento (los padres, de un modo general, conocen a sus hijos mejor que terceros, y por tanto conocen mejor el modo en que pueden favorecerlos). Por otra parte, se relaciona con los problemas asociados a la coordinación de los actores (si el bienestar de todos fuese negocio de todos, surgirían problemas de coordinación y se elevarían los costos de transacción de información.) Obligaciones especiales no consensuales serían una instanciación de obligaciones universales en razón de una reflexión pragmática acerca de la eficiencia.

Aunque estas reducciones argumentativas pueden ser más o menos convincentes, al menos fenomenológicamente son inadecuadas (Loewe, 2010c). A modo de ejemplo, la parcialidad y las obligaciones particulares que se desprendan de la amistad - aunque algunos consideren inapropiado referir a obligaciones de amistad - no parecen ser reducibles a la estructura de un seguro mutuo (tengo una preferencia en la satisfacción de las preferencias de mis amigos para que eventualmente tengan una preferencia en la satisfacción de las mías) o a consideraciones de fair play (el beneficio que obtengo de mis amigos me obliga a retribuirles). Al menos, no sin que algo importante se pierda en el proceso. Es por eso que teóricos de orientación particularista tienden a afirmar 
—contradiciendo la famosa opinión de William Godwin— ${ }^{6}$ que sí hay algo mágico en el pronombre mío: en una decisión trágica entre salvar a un extraño y a la propia mujer «habría sido esperado por algunos (por ejemplo por su mujer) que su pensamiento motivador, completamente enunciado, sería el pensamiento que era su mujer, no que era su mujer y que en situaciones de este tipo es permisible salvar a nuestra mujer.» (Williams, 1981: 18) Desde esta perspectiva particularista, cualquier otra historia que podamos contar acerca de la fuentes de nuestro vínculo normativo, ya sea de tipo kantiano, o de tipo utilitarista (por ejemplo, que la división del trabajo más efectiva exige que cada cual salve a su mujer), aunque no sea necesariamente falsa, implica «un pensamiento de más» (one thought too many): tengo que salvar a mi mujer, porque es mi mujer (compare Goodin, 1988).

¿Qué sucede con el Estado nacional y las obligaciones especiales hacia nuestros compatriotas?

Las fronteras entran de un modo inadvertido en la teoría liberal. Los liberales hablan de derechos humanos o universales, pero de pronto están hablando de derechos ciudadanos. De hecho, en cierta tradición dominante, el espacio de las obligaciones de justicia primarias está delimitado por fronteras políticas. Este es el caso de la teoría de justicia hoy más popular e influyente, la de John Rawls $(1971,1993)$. En sus términos, se trataría de una teoría de justicia social, es decir, una teoría acerca de la justicia de las instituciones más importantes que conforman la estructura básica de la sociedad. La justicia como categoría normativa que se aplique más allá de los Estados — por ejemplo, la justicia internacional o la justicia cosmopolita—o más acá de los Estados — por ejemplo, las relaciones justas entre los sexos, dentro de las familias, etc. - se considera como un desarrollo posterior, diferente y subordinado a la determinación de los principios de justicia social (este análisis en Nussbaum, 2006). Sin embargo, en esta teoría no hay referencia al rol normativo de las fronteras - aunque este tema debiese ser considerado con anticipación a la determinación del foco de la justicia ${ }^{7}$.

6 «El ilustre arzobispo de Cambray era más valioso que su sirviente, y hay pocos de nosotros que, en caso que su palacio estuviese en llamas, y sólo la vida de uno de ellos pudiese ser preservada, dudaría en afirmar cuál de los dos debiese ser preferido. [...] Suponga que el sirviente haya sido mi hermano, mi padre o mi benefactor. Esto no alteraría la verdad de la proposición. La vida de Fenelón seguiría siendo más valiosa que la de su sirviente; y la justicia pura, sin adulterar, habría preferido la que era más valiosa. La justicia me habría enseñado a salvar la vida de Fenelón a costa de la otra. ¿Qué magia hay en el pronombre "mío" que justificaría dejar sin efecto las decisiones de la verdad imparcial?» (GodwiN, 1985: 169-70, trad. DL).

7 En The Law of Peoples, Rawls presenta algunos argumentos relativos al rol normativo de las fronteras. Él refiere a la necesidad de definir responsabilidades de un modo territorial: cualquiera sea la arbitrariedad histórica de las fronteras, el rol del gobierno en cuanto agente de los pueblos es asumir responsabilidad sobre su territorio, sobre el crecimiento de la población y la sustentabilidad ecológica (RAwLS, 1999: 8, 38-39). Si no hay un agente que asuma la responsabilidad, el valor de la propiedad se tiende a deteriorar. En otro sitio he discutido este argumento (LoEwE, 2007a). 
La existencia de fronteras no es trivial paras la teoría liberal y sus pretensiones normativas. De un modo general, fronteras cumplen una doble función: concentran combinaciones de oportunidades en ciertas circunscripciones, e impiden el acceso a todos aquellos que no pertenecen a esas circunscripciones (Cavallero, 2006). De este modo, las fronteras limitan geográficamente el campo de aplicabilidad de los principios liberales y restringen la extensión de sus demandas normativas distinguiendo entre los que están a uno y otro lado. Así, un accidente de nacimiento puede tener consecuencias profundas en la posibilidad de los individuos para perseguir sus planes de vida. Al aceptar las fronteras como legítimas en la implementación y articulación de las demandas normativas, las teorías liberales aceptan como legítimas las consecuencias en la vida que se retrotraen a la contingencia moralmente arbitraria de nacer a uno u otro lado de la frontera, comprometiendo el individualismo, el igualitarismo, y el universalismo, que subyacen al liberalismo.

Por cierto, el desarrollo y maduración de las teorías liberales tuvo lugar junto al desarrollo histórico de los Estados nacionales como los conocemos hoy. Los Estados nacionales fueron el lugar en que los principios liberales se institucionalizaron, es decir, donde la universalidad normativa se hizo institucionalmente vinculante. Sin embargo, no hay traducción simultánea entre las obligaciones y derechos universales o las obligaciones especiales consensuadas y los derechos correspondientes, por una parte, y las obligaciones y derechos que se relacionan con el desarrollo histórico institucional del Estado nacional, por otra. El que esta discontinuidad de la teoría liberal no haya sido suficientemente cuestionada o examinada, se relaciona quizás con la cercanía entre el desarrollo e implementación del liberalismo y el surgimiento de los Estados nacionales, lo que los hace parecer connaturales entre sí. Pero más allá de la contingencia histórica, no hay connaturalidad entre las exigencias normativas que se desprenden de, o que articula la tradición liberal, y su institucionalización estadocéntrica.

Por una parte, es poco convincente retrotraer las obligaciones y derechos que se desprenden de la pertenencia a un Estado nacional a la voluntariedad de sus miembros. Si ya la tesis libertaria según la cual la garantía del derecho de salida transforma toda asociación en voluntaria, y así los derechos y obligaciones correspondientes en consentidos (Kukathas, 1992, 2003) es implausible, es evidente que ella resulta completamente inapropiada en el caso de los Estados nacionales. Tal como Rawls argumenta, ni siquiera el derecho a emigrar transforma en voluntaria la autoridad política $(1993: 22)^{8}$. Esto se debe a que los costos de salida son tan altos que la permanencia no puede implicar voluntariedad ${ }^{9}$.

\footnotetext{
8 «The government's authority cannot, then, be freely accepted in the sense that the bonds of society and culture, of history and social place of origin, begin so early to shape our life and are normally so strong that the right of emigration (suitable qualified) does not suffice to make accepting its authority free, political speaking, in the way that liberty of conscience suffices to make accepting ecclesiastical authority free (RAWLS, 1993: 22).

9 La misma estructura argumentativa, aunque cualificada, aplica también al pretendido consenso tácito de la tradición contractual lockiana. Ni siquiera la existencia de América, un
} 
Por otra parte, afirmar que los derechos y obligaciones propios de las estructuras institucionales del Estado nacional son instanciaciones particulares de obligaciones y derechos universales en razón de consideraciones acerca de la eficiencia que conlleva la convención de que los Estados nacionales se relacionen normativamente exclusivamente con sus miembros y viceversa, es poco plausible. Uno de los grandes problemas con esta estrategia, es que la capacidad de las diferentes naciones para tomar cuidado de sus nacionales se diferencia enormemente. Correspondientemente, si la obligación universal dice que hay que procurar por las necesidades humanas fundamentales hasta un cierto punto, es una mala estrategia estipular que cada nación debe hacerse cargo exclusivamente de sí misma. Esto es evidente en el caso de las naciones pobres o incapaces en tomar cuidado eficientemente de sus ciudadanos. Si bien naciones ricas pueden tomar cuidado de sus miembros eficientemente, no se puede decir lo mismo de las pobres. Cualquiera sea la fuerza intuitiva de esta argumentación reduccionista en el caso de los vínculos familiares, en la medida que la utilizamos para favorecer a nuestros connacionales se debilita: si se trata de cumplir nuestras obligaciones universales de modo eficiente: «¿por qué tiene sentido asignar responsabilidad por los derechos y el bienestar de los suecos a otros suecos y por los derechos y bienestar de los somalíes a otros somalíes si consideramos la cuestión desde una perspectiva global?» (Miller, 1995: 63).

Como punto de partida — que puede y debe ser cualificado- para cualquier teoría que, como la liberal, proponga el carácter vinculante de derechos y obligaciones universales, el que los Estados nacionales sean accidentes, contingencias de la historia y, por tanto, el que las obligaciones y derechos que caracterizan las relaciones dentro de ellos no puedan ser consideradas como consentidos, debe implicar algún grado de incomodidad, al menos mientras no se constituyan como liberales todas las sociedades políticamente organizadas del mundo. En lo que sigue elaboraré, sin pretensión de exhaustividad, cuatro argumentos liberales a favor de la relevancia normativa de las fronteras ${ }^{10}$.

\subsection{Un espacio de seguridad}

El argumento usual a favor del Estado refiere a las ventajas que ofrece a los individuos al generar un espacio de civilidad. Este espacio se obtiene al garantizar la seguridad contra el arbitrio de los otros mediante la garantía de ciertos

lugar aún en estado de naturaleza, puede justificar que la autoridad es legítima en tanto decidimos no emigrar. El costo de salida es demasiado alto. Locke mismo apela en definitiva a un argumento teológico: el estado de naturaleza es el lugar en que Dios nos puso en el mundo. Afirmar que es exigir demasiado de un individuo el que deba emigrar a un lugar en estado de naturaleza sería una ofensa a Dios.

10 Un argumento muy utilizado, refiere al entendimiento de las naciones o culturas nacionales como comunidades de carácter que definen lo justo. De un modo notable este argumento ha sido defendido, entre muchos otros, por Walzer (1984). No me referiré a este argumento porque no es aceptable desde una perspectiva liberal (LoEwe, 2009c, 2012). Para otra consideración de los tres primeros tipos de argumentos cf. LOMASKY (2001). 
derechos que, de un modo mínimo refieren a la libertad y la propiedad. El Estado genera y garantiza un área de protección en que los individuos encuentran cierto grado de estabilidad para poder perseguir sus planes de vida, protegidos de la depredación de los otros ${ }^{11}$. Este tipo de argumentos encuentra buenos precedentes en las diferentes tradiciones contractuales.

Una tesis corriente en la literatura protoliberal y liberal contractual es que la creación del Estado es necesaria porque permite abandonar el estado de naturaleza y, de este modo, asegurar o generar algún bien preciado. De acuerdo con Hobbes, entregarle nuestro poder al soberano para abandonar el estado de naturaleza y así un estado de guerra permanente, es necesario para proteger el interés fundamental en nuestra seguridad. Y según Locke, si bien el estado de naturaleza está gobernado por la ley natural, abandonarlo también corresponde al interés fundamental de cada cual al permitir poner fin al espiral de conflictos y violencia que trae consigo la imperfecta aplicación de la justicia por parte de los individuos. Por cierto, la benevolencia es muy importante entre los elementos teóricos contractuales de la teoría del derecho natural lockiana. Pero a pesar de esto, los individuos son motivados a abandonar el estado de naturaleza porque mediante el contrato pueden promover mejor sus intereses: «for their comfortable, safe, and peaceable living amongst another, in a secure Enjoyment of their properties, and a greater Security against any that are not of it» (Locke, 1960: §95).

Por su parte, la filosofía política de Kant se caracteriza por una pretensión radical que la diferencia de las teorías de Hobbes y Locke. Mientras estas últimas recurren al querer de los individuos, para Kant abandonar el estado de naturaleza sería un dictado de la razón práctica. Con otras palabras: se trataría de un deber $^{12}$. De acuerdo con la tesis de Kant, la constitución del Estado es una idea necesaria ( $K r V$ A 316 s./B 373) y es un mandamiento absoluto (MS 372; 218). Así, el Estado no es el resultado del interés de egoístas racionales o de altruistas proximales (individuos interesados en el bienestar de otros individuos cercanos) en establecer un contrato que asegure derechos iguales en sus comunidades, sino que es una idea necesaria. Con los conceptos de Kant, se trata de una «necesidad de fines» ${ }^{13}$. De este modo, la constitución del Estado es nece-

11 LOMASKY, 2001.

12 Ya en la Crítica de la Razón Pura sostiene Kant que el ideal normativo de una constitución política republicana «que promueva la mayor libertad humana» es, como mínimo, una «idea necesaria» (notwendige Idee) que ha de servir de base no sólo al proyecto de una constitución política, sino a todas las leyes (KrV A 316 s./B 373). Y en la Doctrina del Derecho («Erläuternden Anmerkungen zu den methaphysischen Anfangsgründen der Rechtslehre» -integradas un año después de la publicación) sostiene Kant que la idea de la constitución del Estado es «para cada pueblo mandamiento absoluto de la razón práctica que juzga de acuerdo a conceptos de derecho» y es «sagrada e irresistible» (MS 372/218).

13 La diferencia relevante para la determinación de lo necesario en sí la encontramos en la diferencia propuesta por Kant entre la Necesidad de los Medios (Notwendigkeit der Mittel —necessitatem problematicam) y la Necesidad de los Fines (Notwendigkeit der Zwecke —necessitatem legalem). Esta diferenciación está planteada con anterioridad a las Críticas 
saria porque es la condición de posibilidad de otra cosa que es absolutamente necesaria (unmittelbar notwendig), es decir, es un fin en sí. Y aquello que es un fin en sí es la libertad (Freiheit) y la propiedad (Eigentum) —la propiedad es un fin en sí, porque representa un uso legítimo de la libertad- ${ }^{14}$. Según Kant, la sociedad civil y sólo la sociedad civil, es la condición de posibilidad de la libertad y la propiedad. Por una parte, mediante el establecimiento de un poder coactivo que hace prevalecer el derecho, el orden estatal garantiza la libertad y la propiedad. Por otra parte, la garantía de la libertad y la propiedad debe tomar la forma institucional de un orden estatal. De acuerdo al uso conceptual de Kant, quien entiende el Estado como «la reunión de un número mayor o menor de hombres bajo leyes del derecho» (MS 313/142), cualquier orden que puede garantizar de un modo fáctico la libertad y la propiedad dada por el derecho, debe ser considerado como un Estado.

Ya sea que la instauración del Estado corresponda al querer de los individuos, porque posibilita asegurar bienes preciados, o corresponda a un deber, porque es la condición de posibilidad de la libertad y la propiedad que son fines en sí, en ambos casos ella trae consigo las fronteras que los separan. Si hay buenos argumentos contra la creación de un Estado mundial — como Kant efectivamente afirma-, entonces aceptar estas fronteras es necesario para proteger intereses fundamentales de los hombres o para posibilitar que puedan cumplir con el mandamiento absoluto de la razón práctica. Las fronteras serían fundamentales porque hacen posible al Estado protector de derechos y libertades fundamentales. En ambos casos las fronteras estarían justificadas de un modo derivativo, esto es, en razón de los intereses fundamentales que el Estado protege o en razón de la realización de la razón práctica.

en Investigación sobre la claridad de los principios de la teología natural y de la moral (Untersuchung der Grundsätze der natürlichen Theologie und der Moral (1763)). Kant sostiene que la Necesidad de los Medios no señala ningún tipo de obligatoriedad (Verbindlichkeit), sino que sólo muestra las instrucciones acerca de qué medios nos debemos servir si queremos alcanzar un determinado fin: «es sind gar nicht Verbindlichkeiten, sondern nur Anweisungen eines geschickten Verhaltens, wenn man einen Zweck erreichen will» (Ak. II: 298). En la Fundamentación de la Metafísica de las Costumbres Kant denomina esas instrucciones, imperativos hipotéticos, problemáticos, o técnicos. La necesidad propuesta no puede ser de ese tipo. Si ese fuera el caso, la constitución del Estado sólo sería necesaria en el sentido de ser un medio para otra cosa que podríamos querer o no, y no podría ser, entonces, un mandamiento absoluto (absolutes Gebot).

${ }_{14}$ La vinculación entre propiedad y libertad es característica de la teoría de la propiedad kantiana. Condición de la propiedad no es ni la posesión material fáctica ni el trabajo —como en la teoría de Locke. Éstas no lo pueden ser: hacia la manzana que sostengo en mi mano no puede haber una relación de derecho, aunque yo haya plantado el árbol y lo haya cosechado. Títulos de propiedad son títulos de derecho, y relaciones de derecho sólo puede haber entre hombres. Por tanto, es deber jurídico (Rechtspflicht) actuar hacia otros de tal modo, que lo exterior (utilizable) podría ser también suyo (MS 252/64). Al menos de un modo potencial, los objetos deben ser propiedad de alguno. Cualquier otra regla limitaría la libertad y sería contraria a derecho. He discutido esto en 2016b. 


\subsection{Bienes públicos y fair play}

Más allá de generar un espacio de civilidad, el Estado posibilita el suministro de otros bienes deseables. Incluso sin argumentar a favor de la provisión de derechos sociales, hay buenas razones para argumentar a favor de la provisión pública de un cierto tipo de bienes: los bienes públicos.

Como es conocido, un bien público, o un bien público puro, es aquel que cumple con las condiciones de no-rivalidad y de no-exclusión. Que no es rival, significa que su uso por parte de un individuo no impide su uso por parte de otros. Y que no sea excluyente, significa que si se hace accesible a un individuo, no es posible excluir a otros de su uso. Un ejemplo clásico es una señal radial. Que un individuo acceda a la señal mediante su receptor no rivaliza con que otros individuos que también tienen un receptor puedan acceder a ella; y si la señal es hecha accesible a un individuo con el receptor, no se pude excluir de la recepción a todos aquellos que también tengan un receptor. Los bienes públicos son variados. Ellos van desde puestas de sol, pasando por la confianza social, hasta la seguridad nacional. Una característica de los bienes públicos es que su provisión mediante el mercado es problemática. Esta puede ser ineficiente, o incluso puede llevar al fracaso de los mercados. Así, si su provisión descansara en los mecanismos de mercado, muchos de ellos, valiosos para la consecución de los planes de vida individuales, no estarían disponibles. Por esto es común sostener que, al menos en el caso de ciertos bienes públicos puros, hay buenas razones para coordinar su provisión mediante mecanismos externos al mercado, por ejemplo, mediante la provisión estatal (ya sea a costas de rentas generales o de impuestos específicos a todos aquellos que pueden acceder al bien, independientemente de si lo hacen). Economistas liberales clásicos, como Adam Smith, reconocen las razones a favor de la provisión estatal de bienes públicos (Smith, 2007: 479). Pero incluso libertarios que aspiren a restringir al máximo la acción estatal, privatizando incluso la ejecución de la justicia, o negando cualquier mínimo social que permita la subsistencia, estarían bien aconsejados de aceptar la provisión estatal de ciertos bienes, como, por ejemplo, vacunas o la remoción de los cadáveres de los menesterosos para evitar epidemias.

Si bien la provisión de bienes públicos es terreno fértil para el abuso, es perfectamente defendible como un asunto de principio ${ }^{15}$. Mediante su provisión el Estado posibilita que los individuos dispongan de bienes valiosos que de otro modo no estarían disponibles al perseguir sus planes de vida. De este modo, la legitimidad de la imposición de las cargas tributarias necesarias para su provisión puede retrotraerse al interés de cada cual, un interés que, en razón de las características definitorias de los bienes públicos, no puede ser satisfecho por el mercado. Un argumento a favor de las fronteras es que estas delimitan un espacio institucionalizado apto para la provisión de muchos bienes públicos,

15 Para una defensa libertaria de la provisión de bienes públicos, compare Lomasky (1990: 146-151). 
ya que la clase de los beneficiados se traslapa en gran medida con la clase de los que deben participar en la financiación de su provisión (Lomasky 2001: 66). Por cierto, el traslape no es completo. Pero mientras más completo sea (es decir, mientras se internalice la mayor cantidad de externalidades), mayor será la legitimación de la provisión desde la perspectiva de todos aquellos que son obligados a participar en ella. El caso de la seguridad nacional externa da cuenta claramente de este traslape: la clase de los beneficiados se traslapa en gran medida con la clase de los ciudadanos o los residentes de los que se puede exigir participar en su provisión mediante medidas impositivas, y quizás mediante el reclutamiento. Por el contrario, en el caso de aquellos bienes públicos circunscritos localmente, o de aquellos que se extienden más allá de las fronteras del Estado, hay buenas razones - aunque no concluyentes- para restringir (mediante impuestos o gobiernos locales) o expandir (mediante, por ejemplo, tratados internacionales) la clase de todos aquellos que pueden ser obligados a participar en su provisión ${ }^{16}$.

Se puede articular un argumento similar en relación al principio u obligación de fair play, que se retrotrae a los trabajos de H. L. A Hart (1955) ${ }^{17}$. Este principio implica que los que se benefician de una empresa cooperativa adquieren una obligación de cooperar en ella, porque es la cooperación la que hace posible que cada individuo se beneficie de la práctica ${ }^{18}$. Ciertamente la obligación de fair play puede prestarse para abusos. La crítica corriente ha sido articulada por Robert Nozick, quien imagina un grupo de vecinos que organiza un sistema de entretención de radiodifusión que asigna a cada adulto un día en el cual es responsable de la transmisión. Como residente de la vecindad usted ocasionalmente escucha y disfruta de estos programas sin haber consentido en ser parte de esta práctica. Cuando llega su día asignado ¿está obligado a hacerse cargo? Si bien el principio de fair play afirma que sí, según Nozick la respuesta es «surely not»(1974: 90-95). El abuso surgiría porque se lo entiende como una obligación de participar en una práctica de la que nos beneficiamos aunque no hayamos consentido los beneficios. Este

16 Que estas razones no sean concluyentes tiene sentido: en ocasiones, el beneficio local puede justificar plenamente la obligatoriedad nacional (por ejemplo, si son localidades especialmente desaventajadas); y en ocasiones, aunque los beneficiados más allá de las fronteras del Estado no estén dispuestos a participar en las generación de los bienes, puede haber razones completamente válidas para generarlos a nivel nacional y admitir a los free rider como un hecho de la causa (por ejemplo, en el caso de las políticas climáticas).

17 Según la obligación de fair play: «when a number of persons conduct any joint enterprise according to rules and thus restrict their liberty, those who have submitted to these restrictions when required have a right to a similar submission from those who have benefited by their submission». (HART, 1955: 185).

18 En un escrito temprano RAWLS recurrió a este principio para basar la obligación política, es decir la obligación moral de obedecer la ley. Esta sería «a special case of the prima facie duty of fair play» (1964). 
es el modus operandi de la mafia: otorgar un beneficio para luego exigir algo a cambio ${ }^{19}$.

El principio de fairness de Rawls se basa en la idea de que nosotros debemos contribuir nuestra "parte fair» para así mantener las ventajas que disfrutamos en razón del esfuerzo cooperativo de los otros (1971: 343, 112). Esto tiene sentido. A un nivel fundamental, por ejemplo en un contexto de imparcialidad como el modulado por la posición original, todos compartiríamos un interés en aceptar y en que los otros acepten algún principio de fair play. Esto se debe a que todos tenemos un interés fundamental en no ser explotados por free riders (Barry, 1995), es decir, individuos que se benefician de la acción de otros sin asumir los costes. Este no es sólo el caso con respecto a los bienes públicos y sobre todo a los recursos comunes compuestos por bienes que no excluyen pero que son rivales (bienes que no pueden excluir de su uso a individuos, pero que el uso de cada individuo menoscaba, lo que da lugar a la conocida tragedia de los comunes). Más allá, el interés que compartimos en no ser explotados por free-riders se extiende a todas las prácticas que se dan en la sociedad en tanto empresa cooperativa. Las fronteras serían fundamentales porque posibilitarían, utilizando un concepto de Buchanan, el Estado productivo: "Government is a productive process, one that ideally enables the community of persons to increase their overall level of economic well-being, to shift toward the efficiency frontier.» (1975: 97) La argumentación a favor de las fronteras políticas apunta a que circunscriben el espacio institucional de una empresa en la cual se dan una serie de prácticas cooperativas, dentro del cual los que se benefician de la cooperación coinciden - de un modo amplio, aunque no exacto- con los que participan en ella. De hecho, al considerar a la sociedad como una empresa cooperativa para ventaja mutua, Rawls supone que las sociedades son sistemas cerrados, que todos los individuos están bajo la jurisdicción de un Estado, y que los ciudadanos realizarán una vida completa dentro de las fronteras políticas de su sociedad. Es el traslape entre los beneficiados de la práctica y los que participan en ella lo que hace posible institucionalizar un principio de fair play y de este modo reducir el número de free riders. Sin estos espacios institucionalizados circunscritos por fronteras sería difícil hacer vinculante un principio de fair play en relación a prácticas particulares.

19 Esto no puede confundirse con un permiso para no obedecer leyes con las que discrepemos. Por ejemplo, no sería válido reclamar que una normativa para la protección del medioambiente atmosférico que implica restringir el uso del automóvil no es vinculante, porque no hemos estado de acuerdo con ella. Desde la perspectiva del fair play podemos aclarar por qué en un contexto determinado, en el que determinadas prácticas son efectivas, tenemos determinadas obligaciones. También puede explicar por qué en un contexto hipotético tendríamos una obligación particular. Lo que la obligación de fair play no puede aclarar, es por qué una práctica particular debe continuar existiendo o porqué debería existir. Aun si no nos podemos liberar de los beneficios que trae consigo un medioambiente libre de contaminación - y aun si consideramos este beneficio como una carga negativa porque nos gusta cómo huele y se ve la contaminación atmosférica-, la normativa es vinculante porque hemos sido, directa o indirectamente, parte de su proceso de legitimación política. 


\subsection{Solidaridad y justicia redistributiva}

Los argumentos de las secciones precedentes debiesen ser aceptables para cualquier liberal. Pero es posible ir más allá y articular argumentos que apelen a la función de las fronteras para generar o hacer posible la ejecución de las obligaciones positivas o los derechos sociales (entre otros Tamir, 1993; Fletcher, 1993; Miller, 1995; Calsamiglia, 2000) usualmente cuestionados por los liberales clásicos. A continuación, presentaré tres argumentos a favor de las fronteras en razón de su rendimiento con respecto a los derechos sociales:

Primero: las condiciones para hacer efectiva la justicia redistributiva dentro de una sociedad deben incluir las bases motivacionales que la posibiliten, y las bases motivacionales se encuentran en la pertenencia nacional. Este argumento ha sido avanzado ejemplarmente por David Miller $(1995,2007)$. Miller aboga a favor del principio de la nacionalidad. Este principio sería crucial para el liberalismo, porque posibilitaría el mantenimiento de la justicia redistributiva al hacer posible los lazos de solidaridad social:

Nacionalidad responde a una de las necesidades más exigentes del mundo moderno; esto es cómo mantener la solidaridad dentro de la población de estados grandes y anónimos, de modo que sus ciudadanos quizás no pueden disfrutar del tipo de comunidad que se basa en parentesco o interacción cara a cara. (Miller, 2000: 32; trad. DL)

Para gran parte de la humanidad, la vida ética y sus principios deben referir a una institución social y así acomodar sentimientos naturales hacia familiares, colegas, etc. Así los requerimientos éticos descansan en un conjunto de motivos complejos que llevan a la gente a cumplirlos (Miller, 1995: 58). Desde esta perspectiva las fronteras son fundamentales porque circunscriben espacios de vida e identidad común en que se producen y reproducen los recursos psicológicos motivacionales que hacen posible plantear y cumplir las demandas de la justicia redistributiva.

Segundo: es posible argumentar, como lo hace el mismo Miller, que la justificación de este principio no es sólo instrumental: más allá de posibilitar los recursos motivacionales necesarios para la justicia redistributiva, la nacionalidad compartida sería un tipo especial de vínculo. Con las palabras de Miller: «Esta defensa particularista de la nacionalidad comienza con la suposición que membrecía y vinculación en general tienen significancia ética.» (1995: 65). Naciones serían comunidades éticas, y correspondientemente las obligaciones que debemos a nuestros connacionales serían diferentes y más exigentes que las que debemos a los seres humanos en cuanto tal. Desde esta perspectiva las fronteras son fundamentales porque generan espacios de significancia ética para la determinación de las obligaciones de justicia distributiva.

Tercero: el bienestar tendría un carácter culturalmente subjetivo. De este modo, los medios que permiten alcanzarlo variarían en las diferentes sociedades. Si el bienestar esta mediado culturalmente, en razón de las expectativas idiosincráticas de las diferentes sociedades, entonces los derechos sociales 
estarían mediados por interpretaciones culturales y sociales ${ }^{20}$. En definitiva, las fronteras posibilitarían dar contenido al bienestar y así determinar el tipo de derechos sociales que lo garanticen.

\subsection{Cultura y promoción de la autonomía}

Otro argumento a favor de la relevancia normativa de las fronteras refiere a su rol en la promoción de la autonomía personal que los liberales suelen situar en el núcleo de sus teorías. Una versión cultural nacionalista de este argumento ha sido elaborada por Kymlicka en su justificación de los derechos de las minorías culturales (una discusión de este argumento en Loewe 2007b). Por cierto, él elabora este argumento para justificar regímenes de autogobierno y estructuras federativas, y no necesariamente fronteras políticas entre naciones. Pero sistemas de autogobierno y estructuras federativas también establecen fronteras, aunque más porosas que las que separan a los Estados nacionales (así, hay una discontinuidad entre la movilidad interna, que es usualmente posible y valorada dentro de los Estados nacionales aun cuando tengan estructuras federativas, y la movilidad externa). Sin embargo, el argumento es aplicable al caso de la relevancia normativa de las fronteras entre los Estados nacionales.

De acuerdo a este argumento, el ejercicio de la capacidad autonómica requiere de opciones y criterios de valoración. Al circunscribir espacios culturales («contextos culturales» y «culturas societales» son los conceptos preferidos por Kymlicka en 1989 y 1995 respectivamente) que concentran y ofrecen opciones y criterios de valoración, las fronteras hacen posible la autonomía de los individuos en el proceso de formar, revisar y perseguir sus planes de vida. Indudablemente decisiones tienen lugar en contextos que ofrecen opciones y criterios de valoración. Esto lo reconocen también autores liberales que, como Rawls y a diferencia de Kymlicka, no proponen ciudadanías diferenciadas. Para Rawls debemos disponer de las condiciones sociales necesarias para poder decidir por nosotros mismos lo que es valioso en la vida. Esto se debe a que al decidir cómo guiar nuestras vidas no partimos de novo, sino que examinamos «ideales y formas de vida concretas que han sido desarrolladas y probadas por innumerables individuos, en ocasiones por generaciones» (Rawls, 1971: 563). Como extensión de esta idea, pero ahora cualificada en un sentido cultural nacionalista, Kymlicka afirma que para posibilitar la autonomía personal se requiere de un contexto cultural «rico» y «seguro» (Kymlicka, 1989, 1995):

Los liberales deberían estar atentos al destino de las estructuras culturales, no porque ellas tengan algún estatus moral por sí mismas, sino que porque únicamente disponiendo de una estructura cultural rica y segura es que la gente puede llegar a ser consciente, de un modo vivaz, de las opciones disponibles para ellos, y examinar su valor de un modo inteligente. (Kymlicka, 1989: 165; trad. DL)

20 Un argumento similar en el caso de los grupos culturales en PAREKH (2000); Un argumento similar en vista a las preferencias costosas y los grupos culturales en CoHEN (1999). 
Debido a su relevancia para la autonomía personal, al permitir formar, revisar y perseguir una concepción del bien, Kymlicka sostiene que la pertenencia a una estructura cultural en cuanto contexto de elección (context of choice) debe considerarse como un bien primario rawlsiano (Kymlicka, 1989: 167). $\mathrm{Y}$ en cuanto bien primario debiese ser protegida y fomentada de acuerdo a principios de justicia que garanticen un contexto cultural rico y seguro. Este contexto de elección estaría caracterizado, entre otros elementos, por una lengua y una historia compartida. Kymlicka lo denomina «cultura societal», y afirma que en la modernidad ella adquiere la forma de las naciones. De este modo, la protección de la autonomía personal implicaría la protección de una cultura nacional rica y segura. Desde esta perspectiva las fronteras entre Estados nacionales serían fundamentales para el liberalismo, porque circunscriben aquellos espacios culturales en que es posible la autonomía personal que los liberales aprecian. Correspondientemente, una política que renuncie al control de las fronteras haría peligrar la riqueza y seguridad de este contexto en razón de los importes culturales que esto traería consigo, y así la autonomía que los liberales defienden.

\section{INMIGRACIÓN Y FRONTERAS}

¿Justifican los cuatro argumentos presentados a favor del rol normativo de las fronteras la por los Estados nacionales reclamada potestad discrecional absoluta para controlar la inmigración?

El primer argumento (el Estado protector de derechos y libertades fundamentales) es central. Sin embargo, es importante notar que este argumento no justifica las fronteras de los Estados nacionales como las conocemos hoy. Lo que justifica es la necesidad de la existencia de Estados, entendidos como estructuras institucionales. En este sentido, este argumento no se opone a que las fronteras circunscribiesen espacios institucionales diferentes o, en un extremo, a un Estado mundial que asegurase un espacio de civilidad para todos los ciudadanos del mundo. Con otras palabras: garantizar espacios de seguridad es labor de los Estados como estructuras institucionales, pero no de los Estados nacionales en tanto decantados de procesos históricos. Es razonable contrarrestar que si bien es correcto que las fronteras podrían ser diferentes, ellas son fácticamente las que son, y este debiese ser el punto de partida de la reflexión política filosófica. Pero aun si este argumento fuese correcto, de él no se desprende que los Estados sean normativamente inmunes a las demandas de los inmigrantes por acceder a los espacios de seguridad que circunscriben.

Primero: el compromiso con valores universales implica que los Estados liberales deben considerar el interés de los inmigrantes potenciales. La consideración de sus derechos universales (que protegen su libertad) no puede ser descartada en razón de que ellos están fuera de las fronteras. Si la razón de ser de las fronteras es la existencia de Estados que generen espacios de seguridad 
en que se garanticen derechos fundamentales, entonces son los derechos fundamentales los que tienen primacía en la estructura justificativa. Lo que se deriva es que en la medida en que los Estados puedan aceptar inmigrantes sin poner en peligro el espacio de seguridad, están obligados a hacerlo. Dónde está ese límite es controvertido, tanto por razones empíricas como normativas que refieren a cuán exigente sea la definición de los derechos fundamentales. Pero a un nivel de principios, hay una respuesta meridianamente clara.

Segundo: ciertamente esto no implica abrir las fronteras. Algún grado de control es legítimo aunque no se haya alcanzado el límite señalado. En vista a la misma razón que legitimaría las fronteras (generar espacios de protección en que se garanticen derechos fundamentales), una razón legítima para rechazar inmigrantes potenciales es que estos sostengan ideologías orientadas a violar estos derechos o aspiren a destruir las instituciones que los protegen. Esto no se debe entender como un cheque en blanco a nombre del Estado para discriminar entre inmigrantes potenciales en razón de alguna clase de adscripción (ideológica, política, religiosa, etc.). Esto sería ilegítimamente discriminatorio para todos aquellos que pueden ser adscritos a esas clases pero que individualmente no sostienen esas ideologías ni aspiran a destruir aquellas instituciones. Cualquier selección debe tener lugar sobre una base individual.

El segundo argumento (generación de bienes públicos e implementación de un principio de fair play) tampoco justifica la potestad estatal en el control de las fronteras: en la medida en que no haya razones para considerar que la capacidad productiva de los inmigrantes potenciales es negativa, y en la medida en que no haya razones para considerar que los inmigrantes potenciales violarán el principio de fair play, es decir, en la medida que no haya razones para considerar que se beneficiarán del suministro de bienes públicos sin participar simultáneamente en su generación, y en la medida que no haya razones para considerar que se beneficiarán de prácticas en las que no participarán, no habría razones para no aceptarlos. En sentido estricto, el argumento de los bienes públicos y del fair play es uno a favor de un espacio cerrado de traslape entre beneficiarios y productores del beneficio. En este sentido limitado es un argumento a favor de las fronteras. Pero no es un argumento acerca de la composición interna o la cantidad de individuos dentro de cada uno de estos espacios. Además, y de un modo general, la mayoría de los inmigrantes emigra en edades productivas y después de los procesos de formación, de modo que, a diferencia de los nacionales que disfrutan de los bienes públicos y de los frutos cooperativos por mucho más tiempo y desde antes de comenzar a participar en la producción, los inmigrantes ofrecen una tasa mayor de aporte en la generación de bienes públicos.

El tercer tipo de argumento (fronteras generan solidaridad o delimitan comunidades éticas o dan contenido al bienestar y así hacen posible la justicia distributiva) es corriente en las discusiones políticas relativas a la inmigración. Los inmigrantes, o algunos de ellos, suelen ser considerados como una amenaza a los Estados sociales y sus prestaciones. Pero aunque quizás es uno de los argumentos con más fuerza de apelación en la opinión pública para sostener la 
potestad estatal en el control discrecional de sus fronteras, su fuerza normativa es restringida. Las mismas premisas en que se basa el argumento, y en definitiva esta interpretación del liberalismo, limitan radicalmente la discrecionalidad que se supone el argumento favorece.

De acuerdo a la interpretación fuerte examinada, naciones son comunidades éticas que definen obligaciones especiales hacia los connacionales. Los nacionales y sus necesidades tendrían prioridad por sobre los que no pertenecen a la comunidad nacional en razón de la normatividad implícita en la relación. En razón de estas obligaciones especiales hacia connacionales, las naciones tendrían la autoridad para cerrar sus fronteras frente a la presión migratoria (Miller, 1999, 2007). En esta línea de argumentación, Miller refiere a «hechos relacionales» (relational facts). Este es un tipo de particularismo ético, de acuerdo al cual las relaciones entre las personas son parte básica de la ética, de modo que «principios fundamentales pueden ser vinculados directamente a esa relación» (1995: 50). El vínculo normativo de las obligaciones especiales no consensuales no requiere ser derivado de obligaciones universales (mediante, por ejemplo, argumentos de eficiencia), ni requiere ser reconstruido por referencia a algún tipo de voluntariedad, sino que las relaciones en cuanto tal ya estarían cargadas normativamente.

Pero esta posición es insatisfactoria. Si no hay una perspectiva universal que se superponga a los hechos relacionales ¿cómo determinamos cuáles son las obligaciones implícitas en los hechos relacionales? En la determinación de las obligaciones, este modo de particularismo debe tomar un punto de vista tradicional, por ejemplo mediante la aceptación de una interpretación autoritativa acerca de qué hechos relacionales implican qué obligaciones. O debe apelar a intuiciones compartidas y determinar de algún modo cuáles son las correctas - probablemente apelando a criterios ofrecidos por las interpretaciones autoritativas-. Así se determina las obligaciones existentes y su contenido por recursos a la tradición, y esto perjudica a todos aquellos que tradicionalmente han tenido menos poder de negociación en el establecimiento de las prácticas sociales tradicionales ${ }^{21}$.

Por su parte, la interpretación débil examinada afirma que una identidad nacional compartida juega un papel importante en la generación de la motivación necesaria para implementar los mecanismos institucionales de la justicia distributiva. Como un hecho psicológico estamos más dispuestos a ayudar a aquellos o a compartir nuestras riquezas con aquellos que nos son próximos. Y quizás nuestros connacionales nos son más cercanos que extraños de otras geografías - aunque probablemente esta última suposición no admite un

21 En oposición a esta fantasía de univocidad valorativa y cultural, todas las sociedades son campos de disputa. Dudarlo implica aceptar las interpretaciones autoritativamente vigentes de acuerdo a las elites de turno y así apoyar a los favorecidos del statu quo. No es casual que los grupos con menos poder de negociación —usualmente mujeres y niños- sean quienes más sufren formas de opresión y dominación en las culturas tradicionales (OKIN, 1999). 
escrutinio severo- - Sin embargo, si bien el argumento tiene sentido, no es sostenible afirmar que haya una correspondencia directa entre nuestra motivación y nuestras obligaciones. A la base de esta posición se encuentra una interpretación demandante [siguiendo a Wellman (2000: 555), una versión motivacional sensible] del dictum «deber implica poder». En su lectura usual, este significa que no se debe exigir hacer algo que no se puede hacer. Hay imposibilidades físicas y analíticas que reducen la extensión de lo exigible (por ejemplo, que los hombres vuelen, o que todos ganen más que el promedio). En la interpretación demandante «deber implica poder» se entiende como motivación: «A debe hacer $\mathrm{X}$ » implica que «A tiene una motivación suficiente para hacer X». Este modo de hablar tiene sentido. Hay un sentido en el que no se puede hacer $\mathrm{X}$ sin tener la motivación. Si una acción X puede ser reducida a creencias y deseos, es discutible afirmar que se realiza $\mathrm{X}$ sin tener el deseo correspondiente. Pero de esto no se desprende que haya una correspondencia directa entre nuestra motivación y nuestras obligaciones potenciales: afirmar que la determinación de nuestras obligaciones yace en nuestra motivación, limita nuestras obligaciones de un modo impermisible. En tanto una teoría liberal sostenga el carácter universal de los derechos sociales, se debe atender también al bienestar de los inmigrantes potenciales. En tanto la inmigración haga posible a los inmigrantes acceder a la garantía de los derechos sociales, la referencia a la falta de motivación para ayudar a los no-nacionales no puede ser un argumento normativo, sino que exclusivamente prudencial al momento de decidir la magnitud de ingreso ${ }^{22}$.

El tercer argumento es implausible. Independientemente de la plausibilidad de este tipo de argumentos en el caso de los grupos culturales y sus demandas por derechos culturales (que a mi juicio es muy poca (Loewe 2009a), su extensión al caso de los bienes materiales en razón de las expectativas generadas debido a las idiosincrasias partic ulares de las culturas nacionales, es muy problemática. Utilizando el lenguaje del enfoque en las capacidades, es evidente que la tasa de convertibilidad de bienes en ventajas está mediada por el medioambiente social (Sen, 1992), y que, por tanto, garantizar un funcionamiento particular puede implicar diferentes paquetes de bienes en diferentes sociedades. Pero las particularizaciones culturales del bienestar no se oponen a la determinación del carácter universal de ciertos bienes. De hecho, en tanto no se opte por un particularismo extremo e incompatible con los requerimientos normativos liberales, ellas supone el carácter universal: son instanciaciones particulares de necesidades y aspiraciones humanas universales. Utilizando el lenguaje de Nussbaum en su interpretación del enfoque en las capacidades, las capacidades serían universalmente válidas y estarían expresadas de un modo

22 Miller y Kymlicka, intentan evitar esta conclusión en tanto reconocen que el cierre de las fronteras debe ir acompañado por medidas para mejorar las condiciones de vida en los países de origen de los inmigrantes potenciales (Kymlicka, 1995; Miller, 1999, 2007). 
suficientemente general como para poder ser interpretadas de modo diferente en distintas sociedades (Nussbaum, 2000, 2006) ${ }^{23}$.

El cuarto argumento (las fronteras posibilitan la autonomía personal) es implausible. Esta afirmación no implica una crítica a la tesis de que decisiones tienen lugar en contextos que ofrecen opciones y significados, la que probablemente es correcta. El punto es que esta tesis no implica que las únicas opciones disponibles y los criterios de valoración relevantes al decidir sobre nuestros planes de vida sean exclusivamente aquellos relacionados con nuestra pertenencia cultural o nacional. Esto resulta aún más evidente, al notar que la cultura en este argumento tiene un fuerte componente étnico, incluyendo elementos tales como un lenguaje y una historia compartida. Como ha argumentado Waldron, de la tesis de que cada opción tiene un significado cultural no se sigue que deba haber un contexto cultural definido mediante lenguaje e historia que le otorgue un sentido a todas las opciones disponibles (1995: 106). Las opciones y criterios de valoración pueden provenir de fuentes culturales diversas: «los materiales están simplemente disponibles desde todos los rincones del mundo, en cuanto fragmentos, imágenes y trozos de relatos con mayor o menor significado» (1995: 108). Si esto es correcto, entonces el argumento puede establecer que se requiere recursos culturales y valóricos para formar, revisar y perseguir una concepción del bien, pero no que esos recursos deban referir exclusivamente a una estructura cultural nacional. Si esto es así, entonces el que con la importación de sus tradiciones los inmigrantes hagan peligrar la seguridad o la pretendida riqueza del contexto de elección, no menoscaba la autonomía personal de los miembros de la sociedad de acogida, y por tanto no es un argumento válido para sostener la discrecionalidad estatal del cierre de fronteras.

\section{CONCLusiones}

Al pensamiento liberal subyace una tensión entre las pretensiones universales de la teoría y la aceptación del modelo del Estado nacional como contexto de implementación de sus pretensiones normativas. Esta tensión se expresa especialmente en el caso de la inmigración. La doctrina liberal puede dar cuenta tanto de obligaciones y derechos universales como de obligaciones y derechos especiales consensuales. Pero las obligaciones y derechos que se relacionan con el modelo del Estado nacional no son universales en cuanto a su extensión, y en muchos casos no pueden ser propiamente expresadas como especiales consensuales, sino que son un tipo de obligaciones particulares no consensuadas. Las fronteras de los Estados nacionales determinan quién está dentro del contexto de aplicabilidad de las exigencias normativas liberales. Pero en cuanto doctrina

23 Evidentemente, se pueden estructurar argumentos similares desde la perspectiva de teorías que definen la métrica del bienestar de otros modos. En otro sitio he discutido el Enfoque en las Capacidades en vista al particularismo cultural (LoEwe, 2009b). 
el liberalismo no dispone de ninguna teoría acerca del valor normativo de las fronteras. En sentido estricto, las fronteras son hechos contingentes, accidentes de la historia, irrelevantes para determinar lo que cada cual merece. En este artículo he elaborado y examinado cuatro argumentos relacionados con la tradición liberal para defender la importancia normativa de las fronteras estatales y los he aplicado para examinar la potestad absoluta que los Estados reclaman para controlar sus fronteras en el caso de la inmigración. De acuerdo al primer argumento, las fronteras son normativamente relevantes para la teoría liberal porque posibilitan espacios de seguridad en que se protegen derechos y libertades fundamentales. Para el segundo lo son porque posibilitan un Estado productivo caracterizado por la provisión de bienes públicos y la garantía de un principio de fair play. El tercer argumento afirma que las fronteras son normativamente importantes porque circunscriben naciones, que son el espacio en que la justicia social distributiva es posible. El cuarto sostiene que las fronteras son normativamente importantes porque generan y protegen estructuras culturales en que es posible que los individuos puedan actuar de un modo autónomo. El resultado de esta investigación es que, si bien los argumentos son relevantes, ninguno de ellos justifica la discrecionalidad estatal absoluta en el caso de la inmigración. Desde una perspectiva liberal la porosidad de las fronteras debiese ser mucho mayor que lo que los entendimientos usuales de la tradición liberal suponen y que lo que los Estados que se conciben a sí mismos como liberales implementan con sus políticas migratorias.

\section{BibliografíA}

Аттун, P. S. (1981). Promises, Moral and Law. Clarendon Press, Oxford University Press. BARRY, B. (1995). Justice as Impartiality. Oxford, Clarendon Press.

Buchanan, J. (1975). The Limits of Liberty. Chicago, University of Chicago Press.

Calsamiglia, A. (2000). Cuestiones de Lealtad. Barcelona, Paidós Ibérica.

CAVAllero, E. (2006). "An immigration pressure model of global distributive justice Politics». Philosophy \& Economics, vol. 5, no. 1: 97-127.

Cohen, G. A. (1999). «Expensive Tastes and Multiculturalism». En: Bhargava/Bagchi/ Sudarshan (ed.): Multiculturalism, Liberalism and Democracy. Oxford University Press.

Fletcher, G. (1993). Loyalty. An Essay on the Morality of Relationships. Oxford University Press.

Godwin, W. (1985). Political Justice. Harmondsworth, Middlesex, Penguin Books.

Goodin, R. (1988). «What Is So Special About Our Fellow Countrymen». Ethics, 98:4: 663- 686 .

Hart, H. L. A. (1955). "Are there any natural rights?». Philosophical Review 64 (2).

Höffe, O. (1995). Moral als Preis der Moderne. Frankfurt, Suhrkamp.

Kant, I. KrV: Kritik der reinen Vernunft, primera edición A, Ak. IV: 2-252; segunda edición B, Ak. III: 2-552. Crítica de la razón pura. Traducción de Pedro Ribas. Madrid: Alfaguara, 1998 (incluye ambas ediciones). Esta obra se cita según la paginación de la primera (A) y la segunda (B) ediciones. 
Kant, I. MS: Die Metaphysik der Sitten, Ak. VI: 205-493. La metafísica de las costumbres

( $2^{\mathrm{a}}$ ed.). Traducción de Adela Cortina y Jesús Conill. Madrid: Tecnos, 1994.

Kukathas, C. (1992). «Are there any cultural rights?». Political Theory, Vol. 20, No.1.

Kukathas, C. (2003): The Liberal Archipelago: A Theory of Diversity and Freedom. Oxford University Press.

Kymlicka, W. (1989). Liberalism, Community and Culture. Oxford University Press.

KyмLicka, W. (1995). Multicultural Citizenship. Oxford University Press.

Locke, J. (1960, 1679). The Second Treatise of Government. Laslett, P. (Ed.). Cambridge, Cambridge University Press, 1960.

Loewe, D. (1995). On Nationality. Oxford University Press.

Loewe, D. (1999). «Justice and inequality». En A. Hurrell/ N. Wood: Inequality, globalization, and world politics. Oxford, Oxford University Press.

Loewe, D. (2000). Citizenship and National Identity. Cambridge, Polity Press.

LoEwE, D. (2007). National responsibility and global justice. Oxford, Oxford University Press.

Loewe, D. (2007a). «Inmigración Y el Derecho De Gentes de John Rawls. Argumentos a favor de un derecho a movimiento sin fronteras». Revista de Ciencia Política, 27:2: 23- 48.

Loewe, D. (2007b). «Teorías de justicia igualitaria y derechos culturales diferenciados». Isegoría. No. 36: 275-302.

Loewe, D. (2009a). «Liberalismo igualitario e igualitarismo orientado al bienestar: las demandas de las minorías culturales». Signos Filosóficos, vol. X, n. 20: 25-60.

LoEwe, D. (2009b). «El enfoque en las capacidades y las demandas por derechos culturales». Signos Filosóficos, vol. XI, n. 21: 103-146

Loewe, D. (2009c). «La justicia de la inmigración». Civitas, Porto Alegre, Vol.9, No.3: 496-513.

Loewe, D. (2010a). «Los náufragos de nuestro tiempo. El caso de los refugiados». Arbor, 186:744: 555-570.

Loewe, D. (2010b). «Obligaciones hacia generaciones futuras: el caso Contractual». Veritas, Porto Alegre, 55:1: 21-66.

Loewe, D. (2010c). «Liberalismo, inmigración y justicia global: Obligaciones especiales hacia nuestros conciudadanos». Isegoría, no. 43: 435-458.

Loewe, D. (2011). «Der Umfang der moralischen Gemeinschaft: Einbezug nichtmenschlicher Tiere in einen vertragstheoretischen Argumentationsrahmen». En: Kovács, L./ Brand, C. (eds.): Forschungspraxis Bioethik. Freiburg, München. Alber Verlag.

Loewe, D. (2012). «Obligaciones de justicia: ¿open borders o justicia Distributiva?» $A r$ bor, Vol 188, No 755.

LoEwe, D. (2014). «Justicia y memoria: obligaciones de justicia anamnética». En Andrés Stefane y Gonzalo Bustamante (eds.): La Agonía de la convivencia. Ril editores, pp. 87-99.

Loewe, D. (2015a). «Justicia contractual y los seres del futuro», en: Maximiliano Figueroa (ed.): Liberalismo político. Problemas y desarrollos contemporáneos. Ril editores, pp.205-245.

Loewe, D. (2016a). «Contractualismo y animals: ventajas mutuas e imparcialidad». En: Maximiliano Figueroa y José Luis Widow (eds.): Ética Filosófica. Aproximaciones Contemporáneas. Ril editores, pp.109-144.

Loewe, D. (2016b). «Libertad y propiedad en la fundamentación del Estado y el cosmopolitismo kantiano», en: Juan Ormeño y Miguel VAtTer (eds.): Forzados a ser libres. Kant y la teoría republicana del derecho. Fondo de Cultura Económica. En prensa.

Lomasky, L. (1990). Persons, Rights and the Moral Community. Oxford University Press. 
Lomasky, L. (2001). «Toward a Liberal Theory of National Boundaries». En David Miller \& Sohail H. Hалнмі (ed.): Boundaries and justice. Diverse ethical perspectives. Princeton, Oxford, Princeton University Press.

Maccormicк, N. (1999): Questioning Sovereignty. Law, State, and Nation in the European Commonwealth. Oxford University Press.

Maccormick, N./ Raz, J. (1972). «Voluntary Obligations and Normative Powers». En: Proceedings of the Aristotelian Society, Supplementary Volumes, Vol. 46: 59-102.

Nozick, R. (1974). Anarchy, State and Utopia. New York, Basic Books.

Nussbaum, M. (1996). «Patriotism and Cosmopolitanism». En Joshua Cohen (ed.): For love of country. Martha $C$. Nussbaum with respondents. Boston, Beacon Press.

Nussbaum, M. (2000). Women and Human Development. Cambridge, UK, Cambridge University Press.

O’NeILl, O. (2000). Bounds of Justice. Cambridge, Cambridge University Press.

OKIn, S. M. (1999). «Is multiculturalism bad for women?». En Cohen/ Howard/ Nussbaum (eds.): Is Multiculturalism Bad for Women?. Princeton, Princeton University press.

Parekn, B. (2000). Rethinking Multiculturalism. Cultural Diversity and Political Theory. MacMillan Press.

Rawls, J. (1964): «Legal Obligation and the Duty of Fair Play». En S. Hook (ed.): Law and Philosophy, New York, New York University Press.

Rawls, J. (1971). A Theory of Justice. Cambridge, Massachusetts, Harvard University Press.

Rawls, J. (1993). Political Liberalism. New York, Columbia University Press.

Rawls, J. (1999). The Law of Peoples. Cambridge, Mass., Harvard University Press.

Raz, J. (1988). The Morality of Freedom. Oxford University Press.

SANDEL, M. (1982). Liberalism and the limits of justice. Cambridge: Cambridge University Press. SANDEL, M. (2010). Farrar, Strauß and Giroux.

Sen, A. (1992). Inequality Reexamined. New York, Russell Sage Foundation, Harvard University Press.

Sмiтн, A. [2007 (1776)]: Wealth of Nations. Hampshire, Harriman House.

TAMIR, Y. (1993). Liberal nationalism. Princeton: Princeton University Press.

TAYLOR, C. (1985). «Atomism». En: Taylor: Philosophy and the human sciences. Cambridge: Cambridge University Press. Philosophical papers 2.

WALDRon, J. (1995). "Minority Cultures and the Cosmopolitan Alternative». En: Will Kymlicka (ed.): The Rights of Minority Cultures. Oxford University Press.

Walzer, M. (1984). Spheres of Justice: A Defence of Pluralism and Justice. New York, Basic Books.

Wellman, C. (2000). «Relational Facts in Liberal Political Theory: Is There Magic in the Pronoun 'My'». Ethics, 110: 537-562.

Williams, B. (1981). Moral Luck. Cambridge University Press.

Centro de Investigación en Teoría Crítica y Social

Daniel Loewe

Núcleo Milenio Modelos de Crisis

Escuela de Gobierno

Universidad Adolfo Ibáñez, Santiago de Chile

daniel.loewe@uai.cl

[Artículo aprobado para publicación en diciembre de 2015] 